\title{
Analgesic Effect of Morphine Added to Bupivacaine in Serratus Anterior Plane Block Following Modified Radical Mastectomy. Only a Local Effect? Randomized Clinical Trial
}

This article was published in the following Dove Press journal:

Journal of Pain Research

\author{
Fatma A El Sherif' \\ Ahmad M Abd El-Rahman (D) \\ Ahmed H Othman' \\ Samia A Shouman iD ${ }^{2}$ \\ Mervat M Omran ${ }^{3}$ \\ Nivin A Hassan ${ }^{4}$ \\ Sahar B Hassan ${ }^{5}$ \\ Ebrahim Aboeleuon ${ }^{6}$ \\ 'Anesthesia, ICU, and Pain Relief, South \\ Egypt Cancer Institute, Assiut University, \\ Assiut, Egypt; ${ }^{2}$ Cancer Biology, National \\ Cancer Institute, Cairo University, Cairo, \\ Egypt; ${ }^{3}$ Cancer Biology (Pharmacology \\ and Experimental Oncology), National \\ Cancer Institute, Cairo University, Cairo, \\ Egypt; ${ }^{4}$ Cancer Biology (Pharmacology \\ and Experimental Oncology), South Egypt \\ Cancer Institute, Assuit University, \\ Assiut, Egypt; ${ }^{5}$ Clinical Pharmacy, Faculty \\ of Pharmacy, Assuit University, Assiut, \\ Egypt; ${ }^{6}$ Surgical Oncology, South Egypt \\ Cancer Institute, Assiut University, \\ Assiut, Egypt
}

Background: Serratus anterior plane (SAP) block, a novel regional anesthetic procedure, involves the anterolateral chest wall. Opioid receptors have been found on peripheral nerve terminals, so morphine may have a local action.

Objective: This work aimed at exploring the analgesic efficacy of morphine added to bupivacaine in SAPB in patients for whom modified radical mastectomy was conducted and whether it is a mere local effect.

Methods: Forty female patients were planned to have modified radical mastectomy participated in the study. Patients were randomly divided into two groups; Control group (C): received ultrasound-guided serratus anterior plane block with $20 \mathrm{~mL}$ of bupivacaine hydrochloride $0.25 \%$; Morphine group (M): received the same in addition to $10 \mathrm{mg}$ morphine sulfate. Intra- and postoperative blood samples were taken for the assessment of morphine serum levels. All patients were assessed for VAS scores during rest and movement (VAS-R and VAS-M). Time to the first request and the total amount of the rescue analgesia were recorded.

Results: In group M, Morphine was not detected in the plasma of all patients. Both VAS-R and VAS-M were significantly higher in group $\mathrm{C}$ than in group $\mathrm{M}(P<0.001)$ and $(P \leq 0.003)$, respectively. Time to the first request of rescue analgesia was $8.5 \mathrm{~h}$ in group $\mathrm{C}$ compared to $20 \mathrm{~h}$ in group $\mathrm{M}(P=0.005)$ with a median dose of acetaminophen consumption of $2 \mathrm{~g}$ in group $\mathrm{C}$ compared to $1 \mathrm{~g}$ in group $\mathrm{M}(P=0.006)$.

Conclusion: Ten $\mathrm{mg}$ of morphine, when added to bupivacaine in SAPB, improved postoperative analgesia in patients to whom modified radical mastectomy was conducted. This effect seems to be attributed merely to local mechanisms.

Registration: The registration number of this study is NCT02962024 at www.clinicaltrial. gov.

Keywords: analgesic, morphine, bupivacaine, serratus anterior, modified radical mastectomy

\section{Introduction}

Blanco et al described the serratus anterior plane block (SAPB), ${ }^{1}$ a novel ultrasound-guided regional anesthetic technique. It is indicated for anesthesia of the anterolateral chest wall. SAPB achieves sensory block of the anterolateral wall of the chest by delivering local anesthetics in a fascial plane that is either superficial or deep to the serratus anterior muscle at the level of the fourth and fifth ribs in the mid-axillary line. ${ }^{1,2}$
Correspondence: Ahmed H Othman

Tel +201005098394

Fax +20882086609

Email ahmadhothman@gmail.com 
The addition of opioids or other adjuvants to local anesthetic solutions to improve the quality and duration of the nerve block has got a growing interest. ${ }^{3,4}$ Clinical trials have demonstrated the analgesic effect of intraarticular morphine following arthroscopic procedures, that is not dependent on systemic absorption of the drug. ${ }^{5}$

The synthesis of opioid receptors occurs at the dorsal root ganglions then they are transferred to nerve terminals through axonal route. Stimulation of these receptors leads to the simultaneous activation of both endogenous and exogenous opioid peptides inside inflammatory cells. ${ }^{6}$

The analgesic effect of locally administrated morphine and whether it is due to systemic absorption or it is attributed to a purely local effect is a subject of debate.

This study aimed to explore the analgesic efficacy of morphine added to bupivacaine in SAPB for patients for whom modified radical mastectomy was conducted and whether it is a merely local or a systemic effect.

\section{Methods}

The local ethical committee of the South Egypt Cancer Institute - Assiut University approved this controlled, randomized, double-blinded study. (Ethical committee approval no. 348 on 25/9/2016 and Prof. Ashraf Zidan was the chairperson of the committee) and registered before patient enrollment at www.clinicaltrials.gov under number NCT02962024. All of the study participants gave a written informed consent before commencing the study. The study was conducted according to the most recent version of the Declaration of Helsinki. Forty female patients with breast cancer, 18-60 years of age, class I-II of American Society of Anesthesiologists (ASA), weighing between 50 and $90 \mathrm{~kg}$, and scheduled for modified radical mastectomy were enrolled in the study. Exclusion criteria included a history of bleeding diathesis, sepsis, prior surgery in the axillary region, relevant drug allergy, opioid dependence, cardiovascular disease, and psychiatric illnesses that would interfere with proper perception and assessment of pain, alcohol, or drug abuse. Preoperatively, patients were trained on how to assess their pain by visual analog scale (VAS), from $0-10$ (where $0=$ no pain and $10=$ worst pain imaginable).

\section{Anesthetic Regimen}

In the operative room, an intravenous line was in place in the contra-lateral forearm to the side of surgery. Electrocardiogram (ECG), arterial oxygen saturation $\left(\mathrm{SaO}_{2}\right)$, non-invasive blood pressure (NIBP), and end-tidal carbon dioxide $\left(\mathrm{ETCO}_{2}\right)$ monitoring cables were attached. Anesthesia was induced for all patients with slow intravenous (IV) administration of propofol (2-3 mg/kg), $2 \mu \mathrm{g} / \mathrm{kg}$ fentanyl, and $1.5 \mathrm{mg} / \mathrm{kg}$ lidocaine. IV cis-atracurium $(0.15 \mathrm{mg} / \mathrm{kg})$ to facilitate endotracheal intubation.

\section{Randomization and Blinding}

An online research randomizer (http://www.randomizer. org) was used to randomly assign patients into two groups (20 patients each);

\section{Control Group (C)}

Patients received a serratus anterior plane block with $20 \mathrm{~mL}$ of $0.25 \%$ bupivacaine hydrochloride (Markyrene ${ }^{\circledR}$ Sigma-Tec, Egypt) under ultrasound-guidance injected deep to the serratus anterior muscle.

\section{Morphine Group (M)}

Patients received a serratus anterior plane block with $20 \mathrm{~mL}$ of $0.25 \%$ bupivacaine hydrochloride (Markyrene ${ }^{\circledR}$ Sigma-Tec, Egypt) plus $10 \mathrm{mg}$ morphine sulfate (morphine ${ }^{\circledR} \mathrm{SO}_{4}$; Misr $\mathrm{CO}$ Pharma) under ultrasoundguidance injected deep to the serratus anterior muscle.

A blinded anesthetist that is experienced in the technique has performed the blockade with ultrasound guidance under the direct supervision of a blinded study investigator. The block was conducted immediately after induction of general anesthesia with a high-frequency linear ultrasound probe $(10-12 \mathrm{MHz})$; $\left(\right.$ Sonosite $^{\circledR}$, Inc. U.S.A). Patients were in the supine position, and the probe was over the mid-clavicular region of the thorax in the sagittal plane. Counting the ribs inferiorly and laterally, until the fifth rib in the mid-axillary line was identified. The latissimus dorsi muscle (superficial and posterior), teres major muscle (superior), and serratus anterior muscle (deep and inferior) were identified by ultrasound overlying the fifth rib. Fifty-millimeter $22 \mathrm{G}$ Needle (Stimuplex $\mathrm{A}^{\circledR}$, B Braun, Melsung, Germany) was introduced under real-time ultrasound using an in-line needle technique from a posterior to an anterio-caudal direction. The needle tip was placed deep to the serratus anterior muscle on the surface of the rib between the dorsal and mid-axillary line. The test dose was done with $2 \mathrm{~mL}$ saline to confirm the proper position of the tip of the needle and injectate. Clinical pharmacy prepared the study drugs in sterile syringes and gave them to the applying anesthetist who was blinded to the content of the syringes. 
Fifteen minutes after the block, the skin incision was performed. Anesthesia was maintained by $0.03 \mathrm{mg} / \mathrm{kg}$ cisatracurium and 1-1.5 MAC isoflurane in 50\% oxygen/ air mixture. Ventilation parameters were set to maintain normocapnia.

Blood samples $(2 \mathrm{~mL})$ were obtained from each patient at 30 mins, 1 and $2 \mathrm{~h}$ after giving the block for assessment of serum morphine level at those time points from the contralateral forearm. At the end of the surgery, neostigmine $(0.04 \mathrm{mg} / \mathrm{kg})$ and atropine $(0.01 \mathrm{mg} / \mathrm{kg})$ were used to reverse the muscle relaxant. After extubation, all patients were transferred to the post-anesthesia care unit (PACU).

\section{Post-Operative Follow-Up}

Patients were assessed at baseline (immediately postoperative), 2, 4, 6, 8, 12, 18, and 24 hrs post-operatively for heart rate, mean arterial blood pressure, respiratory rate, and oxygen saturation, and for VAS scores at rest/movement (VAS-R/VAS-M). Postoperative analgesia included I. $\mathrm{V}$. infusion of $1 \mathrm{~g}$ of acetaminophen, whenever VAS $\geq 3$ or when requested. An I.V. infusion of $60 \mathrm{mg}$ of ketorolac if the VAS $\geq 3$ within four $h$ of a previous acetaminophen dose. Time to the first request of rescue analgesia, total consumption of acetaminophen, and the number of patients requested additional analgesia in the $24 \mathrm{~h}$ were recorded. Another blood sample was obtained from each patient at $4,6,12$, and $24 \mathrm{hrs}$ after giving the block to follow up the serum morphine level.

Potential side effects, including chest pain, sedation, assessed by sedation score of $0-4$ ( $0=$ fully awake; $1=$ somnolent but responsive to verbal commands; $2=$ somnolent but responsive to tactile stimulation; $3=$ asleep and responsive to painful stimulation; and $4=$ not responsive), and nausea and vomiting (treated by IV bolus of $10 \mathrm{mg}$ of metoclopramide), were observed and recorded. The observer was blinded to the treatment group assignment.

The collected seven blood samples were immediately put into test tubes with lithium heparin. The plasma was separated by centrifugation at $2500 \times \mathrm{g}$ for 10 mins within 2 $\mathrm{h}$ after collection. Resultant plasma was stored at $-70^{\circ} \mathrm{C}$ until assayed. These samples were used for the determination of plasma concentrations of morphine (LC/MS/MS).

\section{Pharmacokinetic Analysis}

Fifty microliters of plasma were mixed thoroughly with $500 \mu \mathrm{L}$ methanol (Alliance Bio, USA), vortexed $30 \mathrm{sec}-$ onds, and centrifuged for $10 \mathrm{~min}$ at $1400 \mathrm{rpm}$ at $4^{\circ} \mathrm{C}$. Twenty microliters of the clear supernatant were injected into the AB SCIEX LC/MS/MS system (AB SCIEX 3200 Q TRAP, Germany) linked to an Agilent 1260 affinity HPLC system. The analytical column used was Waters X Bridge -C18-5 $\mu \mathrm{m}(2.1 \times 150 \mathrm{~mm}$ Column, Agilent, Germany) at $25^{\circ} \mathrm{C}$. The mobile phase consists of $0.1 \%$ formic acid/water (solvent A) and $0.1 \%$ formic acid/methanol (solvent B), delivered at a flow rate of $0.3 \mathrm{~mL} / \mathrm{min}$. The mass spectrometer was operated in the positive ESI mode with the spray voltage set at 4.5 $\mathrm{kV}$ at a temperature of $450^{\circ} \mathrm{C}$. Quantification was performed with multiple reactions monitoring (MRM), and Morphine ion transitions were: $\mathrm{m} / \mathrm{z}$ 286:165.2, with collision energy set at $28 \mathrm{eV}$.

Analyst 1.5.2 software was used for data acquisition and processing. Calculation was done by a Multiquant software program. Serial dilutions of standards were prepared at concentrations that ranged from 14 to $900 \mathrm{ng} / \mathrm{mL}$ for Morphine in drug-free plasma and extracted as mentioned above to make the calibration curve $(\mathrm{r} 2 \geq 0.99)$ (Figure 1).

The serum morphine level after its regional injection in SAPB through the first $24 \mathrm{~h}$ was our primary outcome measure. The secondary outcomes were the total amount of postoperative acetaminophen consumption, the time to the first request of analgesia, VAS score during rest and movement, number of additional analgesia requested, and side effects.

\section{Statistical Analysis}

Based on previous studies on pharmacokinetics of morphine, ${ }^{7,8}$ It was determined that 15 patients for each group were required for the study to have type I error of 0.05 and a power of $80 \%$, using a confidence interval of $95 \%$. We recruited 20 per group to account for patient drop out, random errors, and additional comparisons.

Data entry and analysis were done using version 19 of SPSS $^{\circledR}$ (Statistical Package for Social Science). Data were interpreted as number (percentage), mean (SD), and median (range). A Chi-square test was used to compare qualitative variables. The Kolmogorov-Smirnov normality test was used to test the distribution of quantitative variables, to select the type of statistical testing accordingly. Normally distributed or parametric data were tested using independent sample $t$-test. Mann-Whitney test was used to compare not normally distributed or nonparametric data quantitative variables. Statistical significance was considered when $\mathrm{P}<0.05$.

\section{Results}

In this study, we explored the analgesic effect of adding $10 \mathrm{mg}$ morphine to bupivacaine locally in SAPB and 


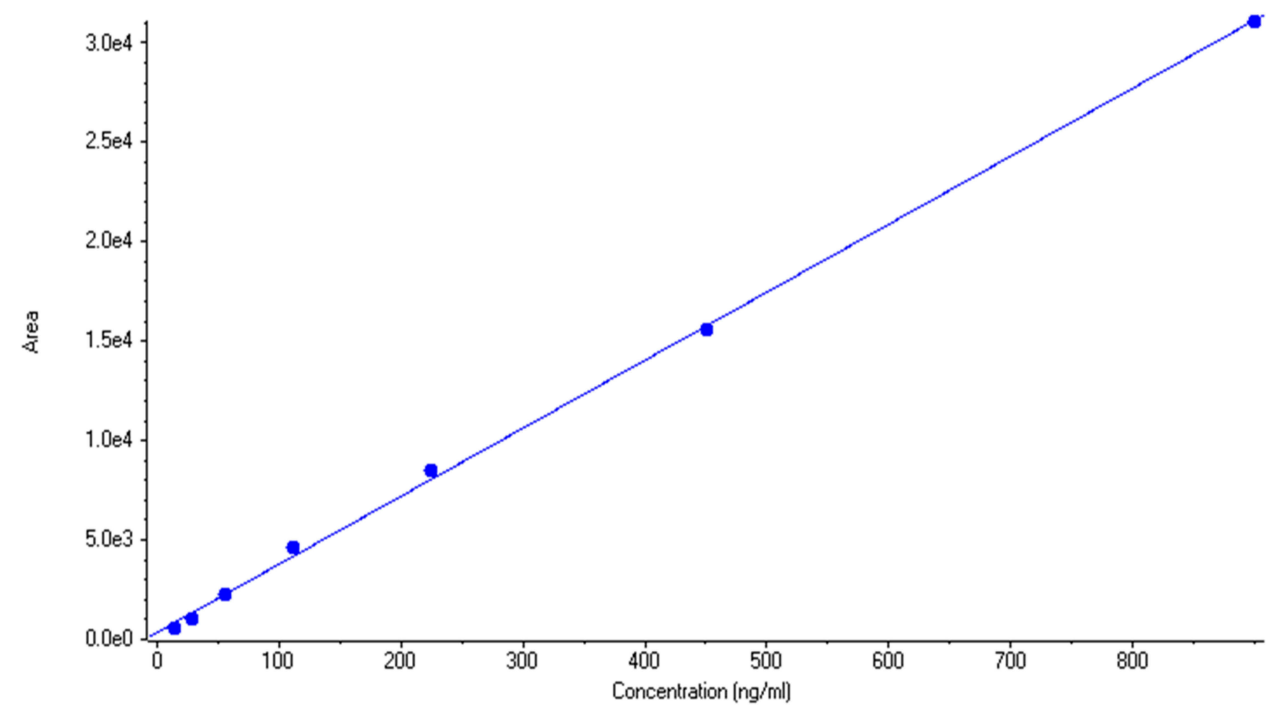

Figure I Calibration curves of morphine ( $14-900 \mathrm{ng} / \mathrm{mL})$.

whether it is a systemic or a local effect through assessment of its serum level at different time points during the $24 \mathrm{hrs}$ of the study period. There was no significant difference in the patients' demographics and clinical data (age, weight, ASA, and duration of surgery) $(P>0.05)$ (Table 1). The participants' flow chart illustrated in (Figure 2).

No observed significant differences in the postoperative hemodynamic variables (mean arterial blood pressure, heart rate, respiratory rate, and oxygen saturation) were $(P>0.05)$.

Morphine was not detected in the plasma samples of the twenty patients, as shown in (Figure 3A). While the typical chromatograms for the detection of morphine were detected at retention time 1.3 mins and are displayed in (Figure 3B). It was noticed that the detected trace concentration in the sample after 30 mins of drug administration was much

Table I Personal and Clinical Data of the Two Studied Groups

\begin{tabular}{|c|c|c|c|}
\hline & $\begin{array}{l}\text { Group M } \\
(n=20)\end{array}$ & $\begin{array}{l}\text { Group C } \\
(n=20)\end{array}$ & P-value \\
\hline & Mean \pm SD & Mean \pm SD & \\
\hline Age (years) & $48.4 \pm 9.5$ & $44.4 \pm 8.5$ & 0.284 \\
\hline Weight (Kg) & $74.7 \pm 6.1$ & $74.4 \pm 6.4$ & 0.865 \\
\hline Duration of surgery $(\mathrm{min})$ & $134.4 \pm 8.9$ & $135.7 \pm 10.3$ & 0.838 \\
\hline ASA score: & & & 0.465 \\
\hline 1 & $16(80.0 \%)$ & 14 (70.0\%) & \\
\hline II & $4(20.0 \%)$ & $6(30.0 \%)$ & \\
\hline
\end{tabular}

Notes: Group M: Morphine group. Group C: Control group. Data are presented as Mean \pm SD (standard deviation) and number and percentage (No \%).

Abbreviation: ASA, American Society of Anesthesiologists. lower than the smallest level of standard morphine that can be detected by our instrument $(14 \mathrm{ng} / \mathrm{mL})$.

Regarding VAS-R/VAS-M, there was a significant increase in VAS-R in group $\mathrm{C}$ compared to group $\mathrm{M}$ at 8 $\mathrm{h}, 12 \mathrm{~h}, 18 \mathrm{~h}$ and $24 \mathrm{~h}(P \leq 0.003)$, and VAS-M at $6 \mathrm{~h}, 8 \mathrm{~h}$, $12 \mathrm{~h}, 18 \mathrm{~h}$ and $24 \mathrm{~h}(P<0.001)$ (Table 2). The number of patients requested analgesia in the first $24 \mathrm{~h}$ was 20 $(100 \%)$ patients in group $\mathrm{C}$ and $3(15 \%)$ patients in group $\mathrm{M}(P<0.001)$. The median dose of acetaminophen consumption was $2 \mathrm{~g}(1-2 \mathrm{~g})$ in group $\mathrm{C}$ compared to 1 $\mathrm{g}(1-1 \mathrm{~g})$ in group $\mathrm{M}(P=0.006)$. The median time to the first request of rescue analgesia was $8.5 \mathrm{~h}(6-13 \mathrm{~h})$ in group $\mathrm{C}$ compared to $20 \mathrm{~h}(18-23 \mathrm{~h})$ in group $\mathrm{M}(P=0.005)$. The number of patients requested additional $60 \mathrm{mg}$ ketorolac was $5(25 \%)$ in group $\mathrm{C}$ compared to 0 $(0.0 \%)$ patients in group $\mathrm{M}(P=0.047)$ (Table 3$)$.

The sedation score showed no significant difference between the two studied groups $(P>0.05)$. Patients who had nausea were $3(15 \%)$ in both groups $\mathrm{C}$ and $\mathrm{M}$. Three patients $(15 \%)$ in group $\mathrm{C}$ compared to two patients $(10 \%)$ in group $\mathrm{M}$ had vomiting with no significant differences $(P>0.05)$.

\section{Discussion}

In this controlled study, we explored the analgesic effect of adding $10 \mathrm{mg}$ of morphine to bupivacaine in SAPB in patients who underwent MRM, and we wanted to check the nature of that analgesic effect to determine whether it is due to a systemic or a local effect.

We found that the VAS-R/VAS-M significantly increased, a higher number of patients requested analgesia, and shorter median time until the first request of rescue 


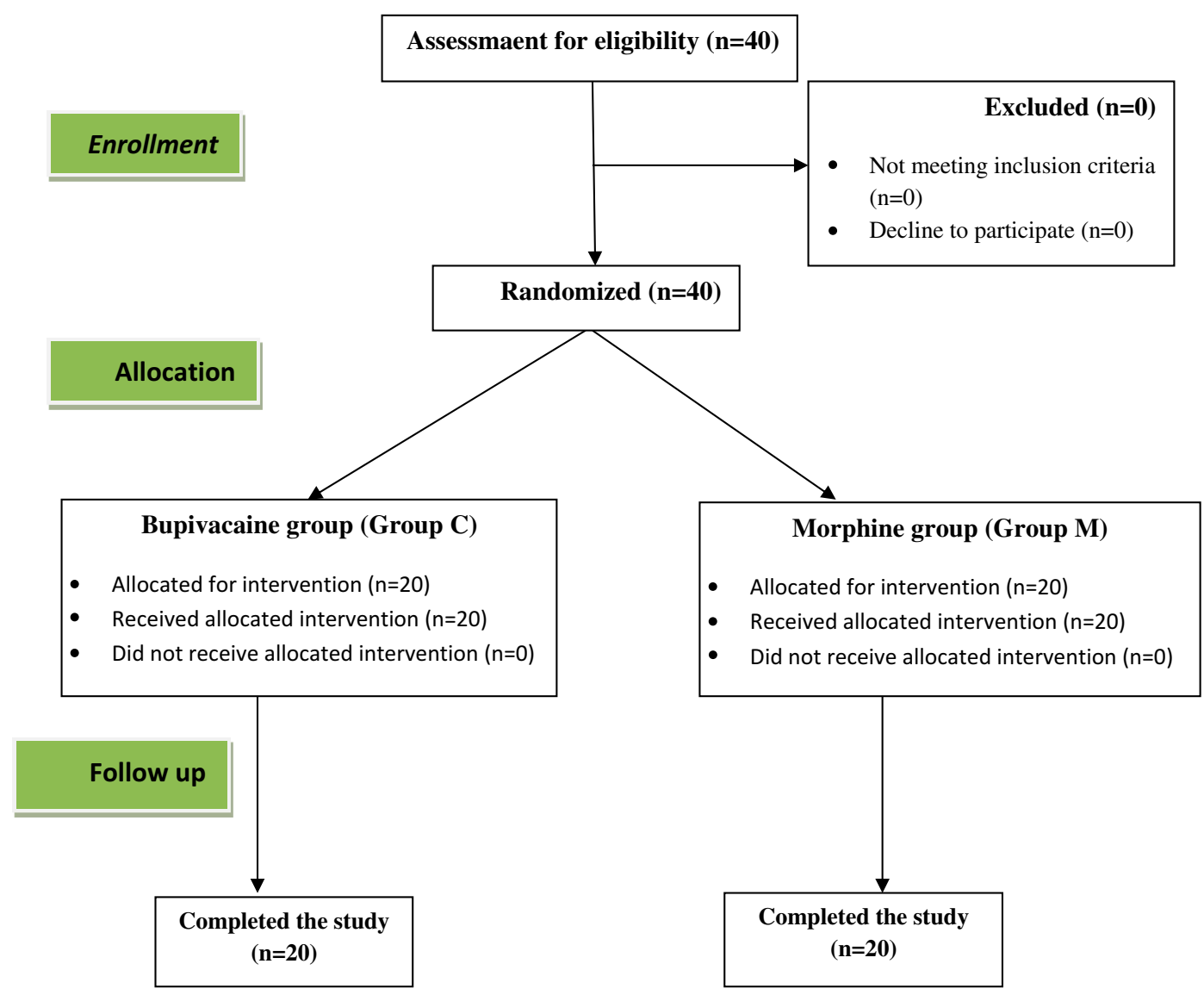

Figure 2 Participant flow diagram.

Notes: Group C: Control group. Group M: Morphine group.
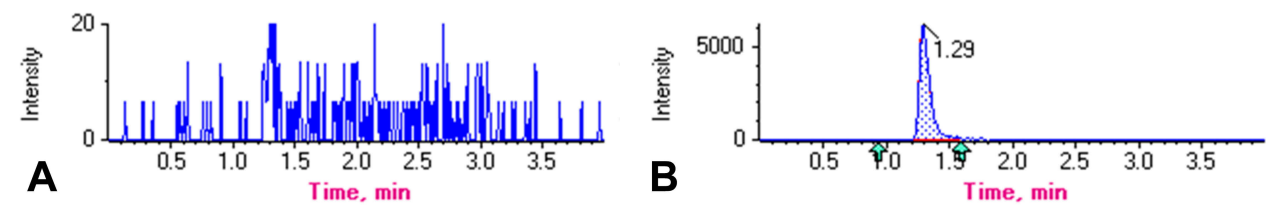

Figure 3 Chromatograms for detection of (A) Morphine in patient plasma at 0.5 hrs after drug administration, (B) Morphine standard with concentration 900 ng/mL.

analgesia in group $\mathrm{C}$ in contrast to group $\mathrm{M}$. At the same time, we could not detect morphine in the systemic circulation except for a trace detected at $30 \mathrm{~min}$ following the block, which is of much lower concentration than the smallest standard level of morphine that can be detected (14 $\mathrm{ng} / \mathrm{mL}$ ). Which points to a pure local rather than a systemic or a mixed (systemic and local) analgesic effect of morphine.

SAPB may be considered the transversus abdominis plane (TAP) block of the chest wall both are interfacial plane block. It blocks the intercostobrachial nerve and the lateral and anterior cutaneous branches from the second to sixth intercostal nerves, where it pierces the external intercostals and serratus anterior muscles at the level of the anterior-to-mid axillary line. Blanco et al proposed a relatively low vascularity and so less absorption and decreased local anesthetic toxicity in this plane which results in reliable and widespread block. ${ }^{1}$

Preemptive analgesia, with its potential benefits, can be achieved by blocking these sensory nerves before skin incision before they leave this plane. Preemptive analgesia in breast cancer surgeries is important for the prevention of primary hyperalgesia, secondary hyperalgesia, allodynia, and central sensitization. ${ }^{9}$ SAPB has a high success rate because it is easy to perform, with minimal incidence of complications.

Previous studies confirmed the effectiveness of SAPB in postoperative analgesia as Khalil et al, ${ }^{10}$ who concluded that it was an effective and safe technique for postoperative 
Table 2 VAS: Visual Analogue Scale

\begin{tabular}{|c|c|c|c|c|c|c|}
\hline \multirow[t]{3}{*}{ Time Point } & \multicolumn{2}{|c|}{ Group $M(n=20)$} & \multicolumn{2}{|c|}{ Group C $(n=20)$} & \multicolumn{2}{|l|}{ P-value } \\
\hline & VAS-R & VAS-M & VAS-R & VAS-M & VAS-R & VAS-M \\
\hline & \multicolumn{2}{|c|}{ Median (Range) } & \multicolumn{2}{|c|}{ Median (Range) } & & \\
\hline VAS. baseline & $0.5(0.0-1.0)$ & $1.0(0.0-1.0)$ & $0.5(0.0-1.0)$ & $1.0(0.0-1.0)$ & 1.000 & 0.435 \\
\hline VAS. 2 & $0.5(0.0-1.0)$ & $1.0(0.0-2.0)$ & $0.5(0.0-1.0)$ & $1.0(0.0-2.0)$ & 1.000 & 0.277 \\
\hline VAS. 4 & $0.5(0.0-1.0)$ & $1.0(0.0-2.0)$ & $1.0(0.0-1.0)$ & $1.0(0.0-2.0)$ & 0.755 & 0.598 \\
\hline VAS.6 & $1.0(0.0-1.0)$ & $1.0(0.0-2.0)$ & $1.0(0.0-2.0)$ & $2.0(1.0-3.0)$ & $0.85 I$ & $<0.00 I^{*}$ \\
\hline VAS. 8 & $1.0(0.0-1.0)$ & $1.0(0.0-2.0)$ & $1.0(1.0-3.0)$ & $2.0(2.0-4.0)$ & $<0.00 I^{*}$ & $<0.00 I^{*}$ \\
\hline VAS. 12 & $\mathrm{I} .0(0.0-1.0)$ & $1.0(0.0-2.0)$ & $1.5(1.0-3.0)$ & $2.0(2.0-4.0)$ & $<0.00 I^{*}$ & $<0.001^{*}$ \\
\hline VAS.18 & $1.0(0.0-2.0)$ & $1.0(0.0-3.0)$ & $1.0(1.0-3.0)$ & $2.0(2.0-4.0)$ & $0.003 *$ & $<0.00 I^{*}$ \\
\hline VAS 24 & $1.0(0.0-2.0)$ & $1.0(0.0-2.0)$ & $1.5(1.0-3.0)$ & $2.0(2.0-4.0)$ & $<0.00 I^{*}$ & $<0.00 I^{*}$ \\
\hline
\end{tabular}

Notes: Data presented as median (range). Group M: Morphine group. Group C: Control group. *Significant p value.

Abbreviations: VAS-R, visual analogue scale at rest; VAS-M, visual analogue scale at movement.

Table 3 Number of Patients Who Received Rescue Analgesia and First Time of Rescue Analgesia (h) and Total Amount of Postoperative Acetaminophen Consumption (g) in the $24 \mathrm{hrs}$ Following Surgery

\begin{tabular}{|c|c|c|c|}
\hline & $\begin{array}{l}\text { Group } M \\
(n=20)\end{array}$ & $\begin{array}{l}\text { Group C } \\
(n=20)\end{array}$ & P-value \\
\hline Request analgesics No. (\%) & $3(15.0 \%)$ & $20(100.0 \%)$ & $<0.001 *$ \\
\hline $\begin{array}{l}\text { First request/ min Median } \\
\text { (Range) }\end{array}$ & $20.0(18.0-23.0)$ & $8.5(6.0-13.0)$ & $0.005^{*}$ \\
\hline $\begin{array}{l}\text { Total acetaminophen dose } \\
\text { Median (Range) }\end{array}$ & I.0 (I.0-I.0) & $2.0(1.0-2.0)$ & $0.006 *$ \\
\hline Additional analgesics No. (\%) & $0(0.0 \%)$ & $5(25.0 \%)$ & $0.047^{*}$ \\
\hline
\end{tabular}

Notes: Data presented as median (range); Number and percentage (No \%). Group M: Morphine group; Group C: Control group. *Significant $\mathrm{p}$ value.

analgesia after thoracotomy. Also reported by Diéguez et al, ${ }^{11}$ and Ohgoshi et $\mathrm{al}^{12}$ to be effective in providing postoperative analgesia in patients undergoing breast and axillary surgery.

The anesthesiologists have been trying to improve the efficacy of postoperative analgesia by injecting opioids close to the nerve trunks or nerve endings. This is based on the fact that the opioid receptors and their endogenous ligands are present in the peripheral nervous system with their effect on the modulation of inflammatory pain. ${ }^{13,14}$

The local analgesic effect of opioids is based on several observations: first, peripheral opioid receptors are present in the nociceptive afferent nerve fibers, and they are silent except in the presence of local inflammation. ${ }^{15}$ Second, morphine and its metabolites, when applied topically to skin ulcers, are largely undetectable systemically, suggesting the local analgesic effect. ${ }^{16}$ Third, several trials found the effectiveness of peripheral opioid injections for local analgesia, such as intra-articular morphine after knee surgery. ${ }^{17,18}$
Local opioid analgesic actions are pronounced in inflamed tissues. This may be attributed to the increased number of exposed opioid receptors and/or increased coupling with G-proteins (the degradation of perineural barriers and passage of agonists results in exposure of opioid receptors). ${ }^{19,20}$

Moreover, the inflammatory milieu may activate previously inactive neuronal opioid receptors. ${ }^{21}$ Morphine may have pro-inflammatory reflex mechanisms in the form of inhibition of excitation of peripheral sensory neurons and the development of long-term excitatory effects in the spinal cord (wind-up). ${ }^{22}$

We could explain the prolonged analgesic effect in the morphine group to be due to its low lipid solubility and low absorption rate in this relatively low-vascularity plane, in addition to the analgesic effect of morphine metabolites, which adds to its analgesic duration. ${ }^{23}$ According to the previous studies in which morphine was added to bupivacaine in regional anesthesia, ${ }^{24}$ we chose the dose of morphine of $10 \mathrm{mg}$ because, according to these studies, it was effective in prolonging the duration of analgesia without serious side effects.

Our results are in accordance with findings described by El Sherif et $\mathrm{al}^{24}$ that adding morphine to bupivacaine in TAP block is effective in the management of postoperative pain with no serious side effects. The analgesic effect of local morphine after iliac crest bone graft harvesting was better than when given systemically. ${ }^{25}$ Also, Senel et al concluded that adding tramadol to ropivacaine prolonged the duration of axillary brachial plexus block and improved the postoperative analgesic efficacy. $^{26}$ Moreover, Saryazdi et al evaluated the 
additive effect of opioids to axillary brachial plexus block and concluded that morphine and pethidine are more superior to other opioids. ${ }^{27}$ Besides, the review by Sehgal et al summarized that opioids could produce peripheral analgesia through its effect on peripheral opioid receptors and described it as potent, receptorspecific, analgesic effects outside the central nervous system. $^{28}$

Human studies have related the analgesic effect of morphine to its plasma concentration. ${ }^{29,30}$ Since the minimum effective plasma concentration of morphine in humans is 20 $\mathrm{ng} / \mathrm{mL}^{31}$

The previous study suggested serum morphine level of $50 \mathrm{ng} / \mathrm{mL}$ as an effective concentration for moderate analgesia. ${ }^{32}$ A recent study reported that systemic analgesic effect was achieved with morphine plasma concentrations of $15-20 \mathrm{ng} / \mathrm{mL}^{33}$

In our study, morphine plasma concentration was much lower than $14 \mathrm{ng} / \mathrm{mL}$, suggesting that there is almost no morphine in the systemic circulation to propose any analgesic effect and that its analgesic effect is a purely local effect.

The serum levels of morphine, morphine-6-glucuronide (M6G), and morphine-3-glucuronide (M3G) were assessed in plasma after topical application of $10 \mathrm{mg}$ morphine gel to skin ulcers, to investigate its bioavailability. ${ }^{16}$ And they failed to detect any of them systemically except in one patient with the largest ulcer surface area.

We believe that this study was limited by the relatively small sample size and single-dose choice of morphine. We recommend further researches with larger sample size and different (smaller and larger) doses of local morphine.

In conclusion, adding $10 \mathrm{mg}$ of morphine to bupivacaine locally administered in SAPB improved postoperative analgesia in patients for whom modified radical mastectomy was conducted. This effect seems to be attributed solely to local mechanisms of action.

\section{Data Sharing Statement}

We are not planning to share any of the data with anyone.

\section{Funding}

No funding was taken to accomplish this work.

\section{Disclosure}

The authors declare no conflicts of interest in this work.

\section{References}

1. Blanco R, Parras T, McDonnel JG, Prats- Galino A. Serratus plane block: a novel ultrasound-guided thoracic wall nerve block. Anaesthesia. 2013;68:1107-1113. doi:10.1111/anae.12344

2. Bouhassira D, Attal N, Alchaar H, et al. Comparison of pain syndromes associated with nervous or somatic lesions and development of a new neuropathic pain diagnostic questionnaire (DN4). Pain. 2005;114:29-36. doi:10.1016/j.pain.2004.12.010

3. Alayurt S, Memis D, Pamukcu Z. The addition of sufentanil, tramadol or clonidine to lignocaine for intravenous regional anesthesia. Anesth Intensive Care. 2004;32:22-27. doi:10.1177/0310057X0403200103

4. Tsai RY, Tai YH, Tzeng JI, et al. Ultra-low dose naloxone restores the anti-nociceptive effect of morphine in pertussis toxin-treated rats and prevents glutamate transporter down-regulation by suppressing the $\mathrm{p} 38$ mitogen-activated protein kinase signaling pathway. Neuroscience. 2009;159:1244-1256. doi:10.1016/j.neuroscience.2009.01.058

5. McSwiney MM, Joshi GP, Kenny P, McCarroll SM. Analgesia following arthroscopic knee surgery. A controlled study of intra-articular morphine, bupivacaine or both combined. Anesth Intensive Care. 1993;21(2):201-203. doi:10.1177/0310057X9302100212

6. Stein C. The control of pain in peripheral tissue by opioids. $N$ Engl $J$ Med. 1995;332:1685-1690. doi:10.1056/NEJM199506223322506

7. de Hoogd S, Välitalo PAJ, Dahan A, et al. Influence of morbid obesity on the pharmacokinetics of morphine, morphine-3-glucuronide, and morphine-6-glucuronide. Clin Pharmacokinet. 2017;56:1577-1587. doi:10.1007/s40262-017-0544-2

8. Kotb HI, El-Kady SA, Emara SE, Fouad EA, El-Kabsh MY. Pharmacokinetics of controlled release morphine (MST) in patients with liver carcinoma. Br J Anesth. 2005;94(1):95-99. doi:10.1093/ bja/aei007

9. Campbell JN, Meyer RA, LaMotte RH. Sensitization of myelinated nociceptive afferents that innervate monkey hand. $J$ Neurophysiol. 1979;42:1669-1679. doi:10.1152/jn.1979.42.6.1669

10. Khalil AE, Abdallah NM, Bashandy GM, Kaddah TA. Ultrasoundguided serratus anterior plane block versus thoracic epidural analgesia for thoracotomy pain. J Cardiothorac Vasc Anesth. 2017;31 (1):152-158. doi:10.1053/j.jvca.2016.08.023

11. Diéguez GP, Fajardo PM, López ÁS, de la Torre Alfaro P, Pensado AC. Ultrasound-assisted approach to blocking the intercostal nerves in the mid-axillary line for non- reconstructive breast and axilla surgery. Rev Esp Anestesiol Reanim. 2013;60:365-370. doi:10.1016/j.redar.2013.04.002

12. Ohgoshi Y, Yokozuka M, Terajima K. Serratus-intercostal plane block for breast surgery. Masui. 2015;64:610-614.

13. Schafer M, Imai Y, Uhl GR, Stein C. Inflammation enhances peripheral mu-opioid receptor-mediated analgesia, but not mu-opioid receptor transcription in dorsal root ganglia. Eur $J$ Pharmacol. 1995;279:165-169. doi:10.1016/0014-2999(95)00150-J

14. Houghton AK, Valdez JG, Westlund KN. Peripheral morphine administration blocks the development of hyperalgesia and allodynia after bone damage in the rat. Anesthesiology. 1998;89:190-201. doi:10.1097/00000542-199807000-00026

15. Elkousy H, Kannan V, Calder CT, Zumwalt J, O'Connor DP, Woods GW. Intra-articular morphine versus bupivacaine for postoperative pain management. Orthopedics. 2013;36(9):1121-1126. doi:10.3928/01477447-20130821-12

16. Ribiero MC, Joel SP, Zeppetella G. The bioavailability of morphine applied topically to cutaneous ulcers. J Pain Symptom Manage. 2004;27(5):434-435. doi:10.1016/j.jpainsymman.2003.09.011

17. Garcia JB, Neto JO, Vasconcelos JW, Ferro LS, Silva RC. Analgesic efficacy of the intraarticular administration of high doses of morphine in patients undergoing total knee arthroplasty. Rev Bras Anestesiol. 2010;60:7-12. doi:10.1016/S0034-7094(10)70001-5 
18. Yari M, Saeb M, Golfam P, Makhloogh Z. Analgesic efficacy of intra-articular morphine after arthroscopic knee surgery in sport injury patients. J Inj Violence Res. 2013;5:84-88. doi:10.5249/jivr.v5i2.303

19. Elvenes J, Andjelkov N, Figenschau Y, Seternes T, Bjørkøy G, Johansen O. Expression of functional mu-opioid receptors in human osteoarthritic cartilage and chondrocytes. Biochem Biophys Res Commun. 2003;311:202-205. doi:10.1016/j.bbrc.2003.09.191

20. Tegeder I, Meier S, Burian M, Schmidt H, Geisslinger G, Lötsch J. Peripheral opioid analgesia in experimental human pain models. Brain. 2003;126:1092-1102. doi:10.1093/brain/awg115

21. Wai EK, Sathiaseelan S, O’Neil J, Simchison BL. Local administration of morphine for analgesia after autogenous anterior or posterior iliac crest bone graft harvest for spinal fusion. A prospective, randomized, double-blind, placebo-controlled study. Anesth Analg. 2010;110(3):928-933. doi:10.1213/ANE.0b013e3181cb3f32

22. Stein C, JD C, Oh U, et al. Peripheral mechanisms of pain and analgesia. Brain Res Rev. 2009;60:90-113. doi:10.1016/j.brainresrev.2008.12.017

23. Beyaz SG. Comparison of efficacy of intra-articular morphine and steroid in patients with knee osteoarthritis. J Anesthesiol Clin Pharmacol. 2012;28(4):496-500. doi:10.4103/0970-9185.101940

24. El Sherif F, Mohamed S, Kamal S. The effect of morphine added to bupivacaine in ultrasound guided transversus abdominis plane (TAP) block for postoperative analgesia following lower Abdominal Cancer Surgery, a randomized controlled study. J Clin Anesth. 2017;39:4-9. doi:10.1016/j.jclinane.2017.03.009

25. Singh D, Gombar KK, Bhatia N, Gombar S, Garg S. Evaluation of analgesic effect of local administration of morphine after iliac crest bone graft harvesting: a double blind study. J Anesthesiol Clin Pharmacol. 2013;29(3):356-360. doi:10.4103/0970-9185.117109
26. Senel A, Ukinc O, Timurkaynak A. Does the addition of tramadol and ketamine to ropivacaine prolong the axillary brachial plexus block? Biomed Res Int. 2014;2014:. doi:10.1155/2014/686287

27. Saryazdi H, Yazdani A, Sajedi P, Aghadavoudi O. Comparative evaluation of adding different opiates (morphine, meperidine, buprenorphine, or fentanyl) to lidocaine in duration and quality of axillary brachial plexus block. Adv Biomed Res. 2015;4:232

28. Sehgal N, Smith HS, Manchikanti L. Peripherally acting opioids and clinical implications for pain control. Pain Physician. 2011;14 (3):249-258.

29. Sarton E, Olofsen E, Romberg R, et al. Sex differences in morphine analgesia: an experimental study in healthy volunteers. Anesthesiology. 2000;93:1245-1254. doi:10.1097/00000542-20001 1000-00018

30. Skarke C, Darimont J, Schmidt H, Geisslinger G, Lotsch J. Analgesic effects of morphine and morphine-6-glucuronide in a transcutaneous electrical pain model in healthy volunteers. Clin Pharmacol Ther. 2003;73:107-121. doi:10.1067/mcp.2003.5

31. KuKanich B, Lascelles BDX, Papich MG. Pharmacokinetics of morphine and plasma concentrations of morphine-6-glucuronide following morphine administration to dogs. $J$ Vet Pharmacol Therap. 2005;28:371-376. doi:10.1111/j.1365-2885.2005.00661.x

32. Berkowitz BA, Ngai SH, Yang JC, Hempstead J, Spector S. The deposition of morphine in surgical patients. Clin Pharmacol Ther. 1975;17(6):629-635. doi:10.1002/cpt1975176629

33. Kandasamy J, Carlo WA. Pharmacological Therapies iv: Other Medications in Assisted Ventilation of the Neonate. 6th ed. Philadelphia: Elsevier; 2017:366-379.e5.
Journal of Pain Research

\section{Publish your work in this journal}

The Journal of Pain Research is an international, peer reviewed, open access, online journal that welcomes laboratory and clinical findings in the fields of pain research and the prevention and management of pain. Original research, reviews, symposium reports, hypothesis formation and commentaries are all considered for publication. The manuscript management system is completely online and includes a very quick and fair peer-review system, which is all easy to use. Visit http:// www.dovepress.com/testimonials.php to read real quotes from published authors. 